\title{
Miguel Fernández, \\ una poética de la revelación
}

ARCADIO LOPEZ-CASANOVA

Universidad de Valencia

Hace ya más de veinticinco años, un joven de las altas y lejanas tierras del Finisterre, con sueños ilusionados de poeta, dejó cielos de orballos y saudades y descubrió el sur. Fue primero Málaga y el azul - la alborozada "Ciudad del Paraíso"-, últimos días del estío, y fue luego, tras mágica travesía del Estrecho, Melilla. Y en Melilla, el encuentro con la figura y la obra de Miguel Fernández.

Aquel joven de entonces - quien ahora os habla, dolorido, desde la memoria del corazón se abrió con aquella aventura venturosa a una amistad que el tiempo fue entrañando día a día, y a un fervor por la palabra en belleza de aquel hombre bueno y generoso -él, que siempre, siempre quiso ser para mí un hermano mayor de bondades-, por una obra - la suya- que es hoy, a esta altura de las circunstancias, una ejemplar y admirable razón poética, razón de amor por la poesía.

$Y$ no se entienda — quiero advertirlo desde las primeras palabras- que esta valoración de su obra responde a vuelos de amistad. Responde sólo - he de subrayarlo- a la consideración de que Miguel Fernández, nuestro poeta, representa en originalidad e intensidad una cima - una de las gran- 
des cimas- de su grupo generacional y de lo que ha sido la historia de la lírica española más reciente.

Ahora bien, esos signos apuntados de su originalidad y de su intensidad como poeta, hay que verlos - hay, de hecho, que interpretarlos- en un doble plano: una ruptura y una disidencia.

La ruptura —n él muy especialmente marcada- se produce frente a la promoción anterior (la primera de posguerra), y lo que ella viene a representar: la palabra de razón histórica. Y en efecto, y desde su primer libro Credo de libertad (1958) ( ¡tan lúcido, tan admirable como Don de la ebriedad, o A modo de esperanza, o Las brasas!, por citar ejemplos representativos), Miguel rompe con lo que entre 1954-1960 - de Canción sobre el asfalto o Pido la paz y la palabra a la antología de Castellet- va a ser la recuperación del yo histórico, de la palabra de razón histórica, de un discurso poético que responde a medidos y rígidos realemas líricos, esto es, a notas creadoras de ilusión de realidad (lo real cotidiano, realismo del mundo y la gente): así, determinada protagonización poemática (como en la novela, una actorialización "vulgar" o "plural"), la importancia que adquiere el desarrollo de la anécdota, las fórmulas expresivas teñidas de coloquialismo, la palabra poética en desaliño...

Pero esta vigorosa ruptura con una vigente - entonces- poética de signo realista, se vuelve asimismo disidencia con los postulados más característicos de su propia unidad generacional, la del medio siglo, la de los poetas que irradian su manifestación a lo largo de la década de los cincuenta.

Disidencia, además, que habrá que valorar en su momento desde dos perspectivas complementarias (pero - creo- igualmente iluminadoras de lo que Miguel Fernández va a representar). Así, y de un lado, su adscripción a un importante y decisivo grupo andaluz dentro de esa unidad generacional (recordemos, de Mantero o Roldán a Julia Uceda, y de $\mathbf{M}^{\mathrm{a}}$ Victoria Atencia o Aquilino Duque a Angel García López, por ejemplo), hasta el momento muy marginado por el eje Madrid-Barcelona, entiéndase Claudio Rodríguez-Brines / Gil de Biedma-Barral-Goytisolo, o lo que es lo mismo $-\mathrm{y}$ conviene ya decirlo con todas las palabras-, dos excep- 
cionales poetas y varios poetas menores que cierta propaganda mitificadora ha querido canonizar.

Y así, y de otro lado o vertiente más decisiva, no compartir lo que, de modo general, se ha venido estableciendo y considerando (y que, desde luego, necesita todavía muchas matizaciones) como poética del grupo desda la antología - Poesía última - que Ribes publica en 1963: la poética del conocimiento.

Pues bien, entiendo que el primer signo de originalidad de Miguel Fernández (y signo ya muy temprano) es presentar frente a esa dominancia de la poética del conocimiento, una poética que yo definiría como de revelación. Dicho con otras palabras, a la figurativización - al menos en las primeras obras de sus campañeros de grupo- de un yo de la intrahistoria personal (una palabra fundante de razón autobiográfica, "mi" vida en "un" mundo, diríamos), el melillense opone - ahí el sentido de esa revelación- una meditación de lo universal trascendente; o, si se prefiere, una palabra poética de radical fundamento metafísico (bien distinto, dicho sea de paso, del que mostrarán, en algunas líneas, Valente o Brines).

Pero ese fundamento metafísico como soporte - y razón última y profunda- de su discurso poético, también presenta otro grado, en él, de altísima originalidad. Y es que ese tal fundamento, con precisión nos remite a una peculiar categorización de poeta y de la dimensión de su universo, de su más profunda visión del mundo.

¿Cuál, pues, esa categorización original? ¿Cuál, en fin, esa dimensión de su mundo lírico? Creo, al respecto, que Miguel Fernández representa, desde luego mejor que nadie en la poesía española de su tiempo, esa condición que Heidegger estableció para Hölderlin (y no extrañará la devoción hölderliniana del melillense) de poeta en tiempo menesteroso. Porque resulta bien sabido- los tiempos menesterosos son los que corresponden a la noche del mundo; y la noche del mundo es la que se significa por la desgracia, a saber, la ausencia de los dioses, la privación de los dones de lo sagrado. De tal manera, entonces; que el poeta en tiempo menesteroso - el que canta, como cantó mi amada y admirada Rosalía de Castro, "luz y progreso en todas partes / pero la duda en los corazones" - ha de estar 
para dar razón de esa ausencia o privación, para interpretar los signos o señales de la desgracia (falta de lo sagrado), y para, proféticamente, confortar acaso a los humanos que habitan esa noche del mundo.

Pues bien, me parece que a esta luz de los postulados heideggerianos - el canto menesteroso, la ausencia de lo sagrado - un gran vector, quizás - me atrevo a decir- su vector más radicado y definidor, de la poesía de Miguel Fernández alcanza especial consistencia, especial relieve y originalidad.

En esa apretada línea de interpretación que propongo, Atentado celeste (1975) vuelve a ser libro axial, tanto en lo que recoge, codifica y condensa (sobre las obras anteriores) como en lo que iluminadoramente proyecta hacia desarrollos posteriores. Y una admirable muestra de esa axialidad nos la puede ejemplificar muy bien el segundo poema de la parte segunda -titulado "Disck Jockey" - , apuntando, precisamente, claro que en oscura clave simbolizante tan definidora de su sistema expresivo, a lo que es la raíz ds esa noche del mundo. Atendamos a su lectura:

“Quien ordena el concierto

¿por qué oculto dispone?

Le tiniebla le cubre

con el haz y la antorcha;

da furor $o$ arrebato

mas si muda el deseo,

nacerá una canción

delgada cual quebranto.

Contempla a quienes danzan

y el que danza le ignora.

Hay tumulto en los cuerpos,

frenesí de ser vivos;

recinto de los ecos,

curvo templo de escándalo. 
Nunca la luz desciende

ni él se yergue en su púlpito.

Al menos la alegría

mostrar debiera el rostro".

En principlo, el texto muestra una clara simulación realista (un significado primero, literal), ya que, al parecer, la voz lírica descriptora dibuja, en rápido trazado, una simple escena de discoteca, música cambiante que suena, cuerpos ágiles y transidos en la danza.

Pero, desde luego, la razón poética última de tan intenso y excepcional texto no se agota en tan elemental literalidad. Desde la propia pregunta del hablante (v. 2, "¿por qué oculto dispone?"), pasando por otros signos de indicio que van quedando diseminados (especialmente los signos de connotación religiosa - templo, púlpito-, o determinadas pautas de contrastes, luz/sombra, presencia/ocultación, etc) nos abren el arcano, el milagro de la palabra que descubre un oscuro, un misterioso trasfondo simbólico.

Ciertamente estamos - y es una fórmula muy peculiar de Miguel Fernández- ante lo que llamaríamos un complejo símbolo escénico, con el que nuestro admirado poeta visualiza admirablemente, y con llamativa modernidad, esa noche del mundo, esa desgracia o ausencia de los dioses, privación de lo sagrado. Recordemos, para una fácil comprensión o recapitulación, unas cuantas notas claves:

1. Una oposicion de actores líricos - primera y básica contraposiciónentre "él" ("quien ordena el concierto") y "ellos" (quienes danzan en tumulto de cuerpos, "frenesí - dice- de estar vivos").

2. La ocultación de "él" - la tiniebla le cubre-, su don de "ver" ("contempla a quienes danzan") y -otra contraposición- la "ignorancia", es decir, la privación de ellos ("y el que danza le ignora").

3. Los atributos respectivos, "él" portador de la antorcha, luz/fuego (pero que queda oculta), y "ellos" habitando las tinieblas ("nunca la luz desciende").

4. La "música" que él —desde su "púlpito" — ordena (y que muda con el deseo), y ese tumulto de la danza - ellos- en el "recinto de los ecos, / curvo templo de escándalo"). 
Quizás, y sobre estas notas subrayadas, no resulte difícil entrar al arcano simbólico, y ver cómo esa noche del mundo queda representada. Esto es, las ocultas señales de lo divino (luz/ fuego, fuerzas vivificadoras), la música —según la tradición pitagórica, seguida luego por san Agustín y Boecio, y que tiene plasmación lírica de fray Luis a Jorge Guillén- como símbolo de la armonía del orden cósmico y del humano (pero rota "en ecos"), la desgracia o desposesión de los humanos (sumidos en la privación o ignorancia - tiniebla-), y -muy impartante- una existencia discordante ("tumulto", "frenesi" en el "recinto de los ecos") que ha perdido sus signos autentificadores. Vida, pues, como radical y dramático vacío.

Claro que a partir de esta lucidez de la desposesión, de esta asunción de la noche del mundo, y muy estrechamente asociado a ella, Miguel Fernández va configurando en su obra poética, con decisivos antecedentes ya en libros primeros, (sobre todo en poemas de Sagrada materia (1967) y de Juicio final (1969), lo que identificaríamos como su mito personal. Para ser más precisos, su original figurativización, su proyección fictiva como poeta - con sus atributos, con su función-, o, lo que viene a ser lo mismo, la máscara actorial que le da representación y que le da voz, dentro del complejo juego polifónico que tanto caracteriza su poesía, su discurso lírico.

Pues bien, y en esa línea, su máscara actorial como poeta nos figurativiza - y no podía ser de otro modo- al poeta en tiempo menesteroso, al que canta desde la noche del mundo, desde la privación de lo sagrado, desde la ausencia de los dioses.

Y justamente por eso, su don - el del canto- ha de cumplir una dramática función, una completa razón; ha de ser, siempre, vidente y profeta. es decir, el que es capaz de evocar los signos de lo sagrado, de interpretar, acaso, las (posibles) señales de lo divino (desde la desgracia, recordemos), y transmitírselas a los humanos, a los que habitan en el vacío de las tinieblas, a los que - como vimos en el texto citado antes- viven alienados en la existencia inauténtica (aquel —recuérdese- "frenesí de los cuerpos" en el "recinto de los ecos").

Mas - y es otro aspecto muy importante— esta función de vidente y profeta, este interpretar — sobre todo- las señales de lo celeste, ha de cumplir- 
los esa figura del poeta, esa máscara actorial tan definidora del sistema poético de Miguel Fernández, en unos concretos ámbitos. Sin duda por eso, en razón de esa función que el poeta se asigna, son recurrentes a largo de su obra determinados signos escénicos, determinados ámbitos en los que él aparece situado. Tal, por ejemplo, la casa, tal la ciudad (o concretos puntos de la ciudad, con marcado relieve de parques, árboles o jardines, y con marcas - señales - temporales, brumas, lluvias...), en tanto en cuanto casa/ciudad (y con los signos complementarios apuntados) son símbolos arquetípicos del centro, y ese centro -0 axis mundi simbólico- puede apuntar en dos direcciones: remitir, de un lado, al propio yo íntimo, al foco espiritual vivificador (alma, espíritu), o remitir, de otro, a espacios sagrados, a ámbitos, entonces, de las revelaciones o hierofanías, a lugares en los que los dioses - la divinidad - puede manifestarse, puede hacer partícipe de sus signos al poeta (ya sabemos, en función de vidente, de intérprete, de profeta).

Pero todavía, y sobre esos dos grandes símbolos — casa/ciudad-, Miguel Fernández construye todo un espacio mítico —es el paisaje, por ejemplo, de SIDEL, que aparece en Atentado celeste-, y sobre ese fondo se (auto)mitifica, a su vez, la propia figura del poeta, que se yergue, así, solitaria y solemne — siempre la soledad—, sabia. fiel — también siempre- a los designios oscuros - la ascura condena- de su tribu. Véase como se representa en "Preludio a una soledad":

"Por trochas de Sidel, campero va.

Sube a las atalayas y contempla

la corola, custodia del rocío;

el autillo volando.

\section{Sueña}

ser nauta, anchura del viaje;

limosnero de otros países,

huidizo en el redil que sólo da breñales,

un patio donde el asno circunda aquel brocal.

desolación, costumbre del hastío. 
En holocausto quedas:

puede sólo el que olvida

y regresas de nuevo a la tribu, que ajena,

afana sus labranzas,

e ignora que tú sólo sueñas tus soledades”.

Pero - y sería un tercer y último aspecto, no menos clave, de su poética de la revelación一, en razón de todo lo anterior está, finalmente, cómo Miguel Fernández entiende la función de la poesía.

En esta línea, ya se ha subrayado abundantemente el relieve que la reflexión metapoética tiene en toda su poesía ( $y$, de modo especial, en sus últimos libros). Ahora bien, también esta reflexión alcanza en él atractiva originalidad, de modo que su discurso metapoético se aparta de ejes anteriores —el que desde el esencialismo desarrolla Juan Ramón Jiménez- y posteriores, el de los llamados novísimos (en su segunda etapa).

La reflexión de Miguel Fernández se orienta (al menos en su vector radical, fundamental) a otorgar a la poesía - a la palabra poética - un signo sagrado; entiéndase bien lo que quiero decir: el canto menesteroso del poeta (profeta) es intérprete de la ausencia/señales de los dioses; luego, obviamente, ese canto - ahí el sentido de lo sagrado- está para dar fortaleza a los que habitan la noche del mundo, y para transmitirles - y con ello vivificarloslos mensajes (el sueño memorial) de lo divino, de lo celeste. Dicho de otro modo (y ya lo dejamos apuntado antes), sólo el poeta es el vidente capaz de acercarse al misterio, de entrar con entereza en el abismo. Oigase, a esta luz, el poema "Baño nocturno", en el que el poeta vuelve a jugar con marcadas contraposiciones, manejando, además, un complejo abanico de símbolos:

"Me has dado plena luna

para ver qué acontece.

Los bañistas hundían sus cuerpos en las linfas, y el abismo guardaba sus medusas

y era gozo flotar entre la nada

que un murmullo repite cuando en la orilla muere. 
Quien los ojos penetra por ignoto coral, adivina tan solo lo que encierra el misterio.

Allí sobrecogido aguarda el relicario de quien su vida ahoga, cofre que fue pasión y sales ocultaron, placer de hundir las manos y nada queda asido.

Cuerpo tuyo acaricia un despojo infinito y sumerges tu vida en un mundo que ignoras.

Tan solo un resplandor en los cielos preside; plenilunio en la mar, la tiniebla en lo alto".

Sobre el que podríamos esquematizar los puntos (esenciales) siguientes: (I) La plena luna, como señal iluminadora (y mistérica) de lo celeste, símbolo, también, del conocimiento indirecto, de la función imaginativa, de la luz en la inmensidad tenebrosa:

\author{
"Me has dado la plena luna \\ para ver qué acontece.
}

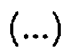

Tan solo un resplandor en los cielos preside".

(II) La noche y el mar como ámbitos de transformaciones, de procesos de morir/renacer, o de ignorancia/búsqueda-saber:

Los bañistas hundían sus cuerpos (...) / el abismo guardaba sus medusas (...) Quien los ojos penetra por ignoto coral (...) $\mathrm{Y}$ sumerges tu vida en un mundo que ignoras (...)"

(III) Tensión, otra vez, de luz (plenilunio en la mar) y tinieblas (en lo celeste). 
(IV) EI ignoto coral, como lugar, —oculto, profundo- que guarda los dones preciosos que acaso pueda ofrecer el misterio del abismo (sentido último de la vida).

A esta luz — sentido sagrado de la poesía, palabra como don vivificador que fortalezca en la noche del mundo a los humanos, y poesía, además, como vía de conocimiento (o revelación) último, el poema que significativamente - posición relevante- cierra Entretierras (1977), y que no menos pertinentemente se titula "Reencarnación en la palabra", me parece que puede ejemplificar de modo admirable, y sin negar, desde luego, otras interpretaciones, esa clave de la reflexión metapoética - tan singular, tan original- de Miguel Fernández. Recordemos al respecto un fragmento:

"La poesía es lo que no se descubre;

parecida a la muerte, pero en vivo.

Ella surge del fondo de un negro tabernáculo que es la meditación.

(...)

Das la vida en aliento, pues calor sólo impone quien lo real inventa ya que lo que transcurre, fue creado por otros.

Es igual que ese cuerpo que tendido fenece, lerdo en las profecías que redimen su aura y es soez fingimiento ya que tan solo existe aquello que libera tanta muerte diaria".

He de terminar ya. Y ahora, en el cierre, quiero traer al hilo y al vuelo de mis palabras aquella voz — verso vivo- herida por el rayo, aquel otro Miguel de la pasión y la elegía, cuando escribió: 
"Muere un poeta y la creación se siente herida y moribunda en las entrañas".

Sí, ciertamente, sobre todo cuando ese poeta —ejemplo de honradez, de generosidad, de tan íntimas intensidades, amigo, hermano mayor, maestro querido- se llama para siempre en el corazón de todos Miguel Fernández. 